\title{
Models and Technologies to Manage the Institutionalization of Sustainable Innovative Development of Meso-Systems
}

\author{
Marina V. Shinkevich \\ Aleksey I. Shinkevich \\ Kazan National Research Technological University, 420015, Kazan, Russia. E-mail: ashinkevich@mail.ru
}

Liudmila A. Ponkratova

Amur State University, 675027, Blagoveschensk, Russia

Natalya V. Klimova

Kuban State Agrarian University, 350044, Krasnodar, Russia

Guzel F. Yusupova

Kazan (Volga region) Federal University, 420008, Kazan, Russia

Irina V. Lushchik

Moscow University named by S.Y. Witte, 115432, Moscow, Russia

Tatiana A. Zhuravleva

Financial University under the Government of the Russian Federation, 125993, Moscow, Russia

\section{Doi:10.5901/mjss.2015.v6n6s2p504}

\section{Abstract}

The relevance of the study is reasoned by the lack of manifestation in the Russian context of innovative factors of sustainable economic development and by the need for institutionalization and the development of management technologies for formation of prospective trajectories of development, creating incentives for innovation at enterprises, industries and in the national economy as a whole. The aim of the study is the search for and development of models and management technologies of institutionalization of meso-systems' innovative development. The leading method is the process modeling method of sustainable innovative development's management of economic systems on the basis of systematization of factors and trends in terms of types of economic activity. The article summarizes the ideas about model dependencies within the innovative development of economic systems, a typology of institutions for innovation development is proposed, a number of model solutions to the problems of institutional gaps is offered in order to supply the chain of innovative products and approaches to the effectiveness' evaluation of the institutionalization of sustainable innovative development are discussed. The materials of the articles - managerial and methodological solutions are of practical value for the following fields and sectors of innovation development: regulation and monitoring of innovation activities of enterprises, objects of regional innovation infrastructure and technology transfer for innovation-active enterprises in the field of manufacturing and other Materials articles - managerial and methodological solutions are of practical value for the following fields and sectors of innovation development: regulation and monitoring authorities of enterprises' innovation activities, agencies of regional innovation infrastructure and transfer technologies, for innovation-active enterprises in the field of refining manufacturing, etc.

Keywords: institutionalization, innovation development, meso-systems, innovations' development institutions, efficiency. 


\section{Introduction}

\subsection{The relevance of the problem}

Innovative development management of multi-level economic systems is alternative in the content and composition of the governing and controlled parameters. Largely the process organization is affected by the selected management paradigm (cybernetic or synergistic), which in its turn is determined by the composition and structure of the prevailing phenomena and processes on the system-level, organizational-economic and industrial relations, resource, institutional, infrastructural, industrial prerequisites and a significant number of other factors. The presence of unique sets of characteristics of economic systems implies the relevance of the research and development of such management techniques which would allow create a fine tuning of the system, which is particularly urgent for innovative sectors of the economy. The fulfilling of this requirement means the importance of innovative development management models and technologies study and selection of the most demanded technologies in the modern world which meet the realities of the global crisis phenomena in the economy and features of existing models in organization of industrial innovative activity. In a number of studies in this area the following researches should be noted (Leydesdorff, 2005; Nelson \& Winter, 1982; Perez, 1985; Shinkevich, 2005).

In a cyclical (of crisis) conditions of phenomena and processes in the economy as a result of import substitution an important factor in maintaining and increasing of economic growth and the gradient of the value added into the national economic system becomes the sustainability of innovative development since Russian innovation factors of sustainable economic development appear to be insufficient. So, the theme of their institutionalization, management technologies development how to form the prospective trajectories of development, creating of incentives for innovation by enterprises and industries of the national economy as a whole become very relevant. In this regard, works of (Williamson, 1985; Silverberg \& Verspagen, 1995; Kleiner, 2006; Lazonick, 2006; Shinkevich, 2012; Krugman \& Venabies, 1995; Mensch, 1985) are worth to note.

The relevance of the article is confirmed by the priorities and organizational forms of reforming in the Russian sectors of science, education and production, actively ongoing, but not always taking into account the institutional features of the national economy. In addition, in the present times new methodological approaches are demanded to the assessment of the effects after economy modernization and forecasting of their results. Among the researchers of the effectiveness of the institutionalization in the Russian economy can be referred, for example, (Katkalo, 2003), (Tatarkin \& Romanova, 2008).

\section{Methodological Framework}

\subsection{Theoretical framework of the research}

As a theoretical basis of the article the management theory, theory of innovation, new institutional theory, the evolutionary theory of innovation, the theory of cyclical behavior of innovative development, the theory of transaction costs, the theory of the effectiveness of economic phenomena and processes can serve.

\subsection{Research methods}

When obtaining scientific results the general scientific and specific methods of knowledge were used: the method of formalization; the dialectical method; the method of analogies, analysis and synthesis; methods of systemic, structuralfunctional, economic-mathematical and simulation modeling; method of multivariate statistical analysis; comparison; index methods; matrix methods; forecasting methods.

\subsection{Research stages}

The study was conducted in three stages:

- the first stage is the preparatory stage during of which approaches to the modeling of innovative development were generalized, the existing and used in the Russian context modernization management technologies on the meso-level were systematized, the techniques of efficiency estimation in modernization processes were studied;

- the second stage - the main stage - when adaptation of neo institutional approach to the management 
process of innovative development of meso economic systems was carried out and a model of value chains completing on the example of medium economic activities was developed, a methodology to assess the effectiveness of the institutionalization of innovative development was developed;

- the third stage - the final stage when systematization, interpretation and synthesis of research results were carried out; refined theoretical conclusions were refined; the obtained results' processing and presentation were carried out.

\section{Results}

\subsection{Innovation development models' evolution at the meso level}

Analysis of management models' evolution at the meso and macro level allows to draw some conclusions: the most important prerequisite of innovative development management is the goal-setting in this area, which does not always reflect the objective laws of systems' economic development; currently at the macro level the understanding of the importance of economy's innovative development and modernization, its openness ensuring are stimulating moments; "openness" of the Russian macroeconomic system should be relative, by analogy with similar models of other national economies' economic development; the rationality of this model is reasoned by the emphasis on the most important laws of demand in innovation at the micro level: technological innovations are relevant for production only under the conditions when the effect from their implementation exceeds the incentive for businesses to save on labor power quality.

Innovations consistently were first considered as exogenous factors of economic development, following them, there were models with endogenous technological progress and their transferring into the category of endogenous is a necessary condition for improving of innovative development management of meso-systems; the endogenous factor of innovation in economic development involves the institutionalization of the fundamental processes of system's effective changes' generation, which are manifested in a sequential account of as neoclassical so evolutionary theories of institutional factors of innovative development. In Fig.1 a systematization of innovative development's factors of mesosystems is presented.

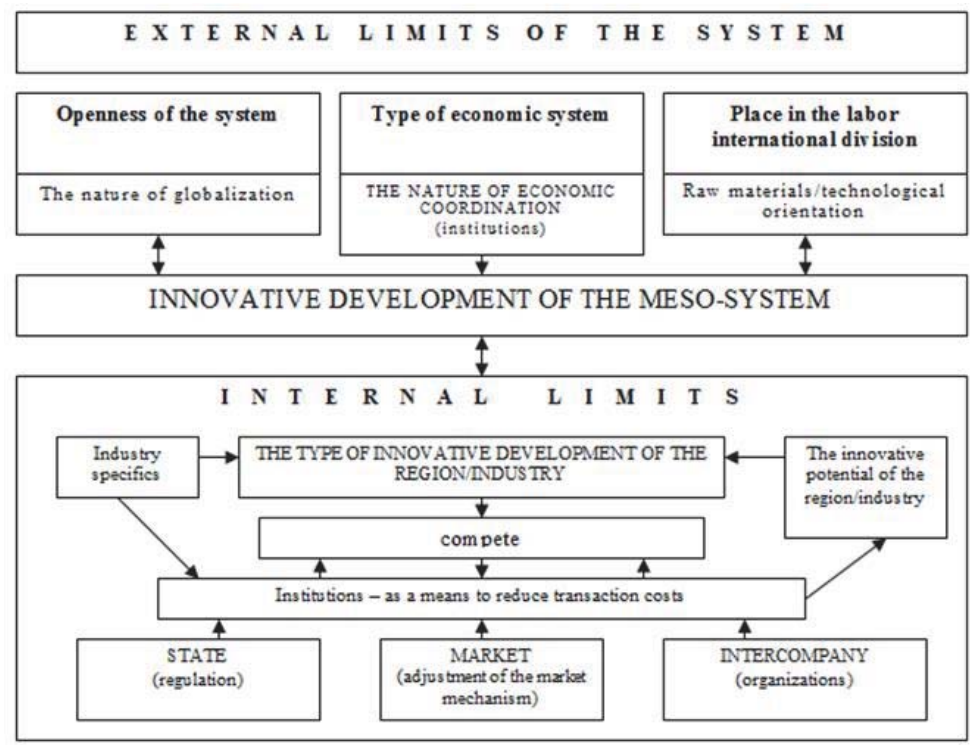

Figure 1. The hierarchical model of interaction between factors of meso-systems' innovative development

In innovative development management there is a necessity of taking into account the cyclical nature of economic systems' innovative development, which is important taking into account the existing asynchronous phases of industries and economic activities of material production; important thing is also the need to maximize at industrial and inter- 
industrial levels and within the national (regional) supply chains of added value as domestic fundamental incentive to implement innovations; regional and macroeconomic systems in this case receive not only external stimulus to the development of "intermediate" industries in the case of resource availability, but also to the development of the full innovation cycle.

It is believed that the institutional models of fundamental incentives' formation for innovations' implementation can be considered as an alternative of economic modernization "from above" and at the same time to ensure the sustainability of economic development of innovative business systems.

The most important relations in the framework of the existing models to stimulate innovations in the Russian context are the following: the stability/instability of innovative development in the active phase of the crisis as a result of balanced (high tech industry) / unbalanced (medium industry) distribution of newly created added value between the participants of a market transaction (within the framework of the production function) is revealed; the technological Pat situation of low-tech industries' innovative development at a steadily low level of the latter is revealed; the nature of innovative development transaction effect is diagnosed and economic activities' kinds with positive (transaction costs' reducing in the course of innovations' development and the increase of market power) and negative (reverse situation) transaction effect are allocated; the imbalance of innovations' reproducing in the industry (in Russian conditions and for developing countries) due to low in comparison with developed countries the productivity of investment into innovative projects, with similar proportions of resource provision of research and development (R\&D) is justified; the insufficiency of existing instruments for innovations effectiveness evaluating to study the sustainability of economic systems innovative development is revealed.

\subsection{Typology of institutions for innovation development}

The models' developed typology takes into account the specifics of the management object (innovative enterprise, macro technology, Institute of development), the management subject - modernization agents (entrepreneur, technology platform, Institute of development) and management technologies (compensatory mechanism of internalization of innovations' externalities; innovative products supply chains' management; the mechanisms of industrial and competition policy aimed at maximizing the added value at the meso level).

At the micro level within the framework of the synergetic approach as agents of development should be considered innovative enterprises as institutions of institutionalization. The basis for the institutionalization of sustainable innovative development of the enterprise is the formation of the trajectories of innovative development of the company, under which it is possible to "extend" innovative development, slowing the degradation of innovative products for the processing of macro technologies. In turn, the institutional trajectories are formed under the impact of important factors which should be taken into account: increasing returns (analogy of the scale efficiency in the framework of institutional theory, associated with high costs of passing on new technology) and the markets' imperfections, characterized by significant transaction costs. With this the specific technology, in innovation encouraging, in a number of other advanced technologies, is the "co-compete".

The thing that hampers innovation development is preferential adherence of foreign and Russian entrepreneurs after the "annuity- hunter" model (Baumol, 1990), along with the positive position of sustainable innovative development of "creative destruction" model (Schumpeter, 1982).

The choice of the model of the first type by Russian enterprises is reasoned by the lack of basic incentive for innovation. Therefore, the project of institutionalization should encourage enterprises to sustainable economic development by stimulating the quantity and quality of human capital, measured for plant personnel.

The object of institutionalization at the meso-level is the macro-technology, and the agent of development - the management body of a special Institute for the development - technological platforms. Economic mechanism of functioning of the latter is based on the developed dynamic model of innovation, and as a management technology the institutional synergetic management model of sustainable innovative development at the meso level is proposed. This transfer of innovative interactions into institutional form requires the use of not only market and competitive approach, but also the innovations externalities' reflection throughout the chain of innovative interactions, which are not of the purchase and sale transaction by nature. Moreover, it is believed that the formation of technological platforms which is not accompanied by corresponding positive externalities is unstable. Therefore, the institutionalization of additional factors to ensure the sustainability of innovative development in the form of processes and technologies of self-organization of innovation active enterprises is needed.

The model of institutionalization at the macro level are the development institutions, the typology of which is presented in figure 2 . 


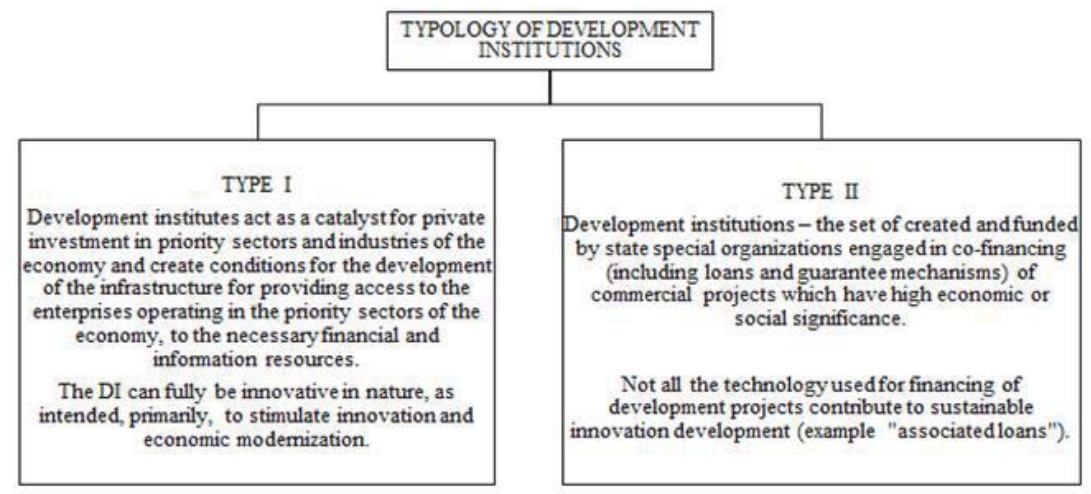

Figure 2. The typology of development institutions ( $D$ \& i) at the macro level

In spite of the large number of mentions of the term "development institutions" their scientific definitions in the economic literature are rare due to the diversity of definitions of proper institutions. The scientific interpretations of the development institutions are found both in wide and narrow (financial) format, which is most common in the Russian practice of management. Under the development institutions a tool is understood for the institutionalization of sustainable economic development of innovative economic systems aimed at resource provision of sustainable incentives to innovate activity, accompanied by positive externalities. When adjusting the innovation sphere it is important to take into account the model solutions' complementarity of the existing model of funding innovation at the macro level. It is believed, a landmark in the institutionalization of effective models of innovative development should be a clustered and meso-corporate funding model of innovations, based on the project approach.

\subsection{The proposed approach to eliminate the institutional gaps in the supply chain of innovative products}

Important from the point of view of managerial approach formation to the institutionalization of sustainable economic development is a following set of scientific problem areas: associated with the definition by economic content the category "economic stability" (static characteristics) and "sustainable economic development" (dynamic characteristics); determining of the contribution of innovation activity and its specificity as a factor of sustainable economic development; classification of factors determining sustainable development; complex of management technologies to form trajectories of sustainable development.

Systematization and study of solutions to scientific problems noted has allowed to develop institutionally-synergetic model of management of sustainable innovative development at the meso-level, key elements of which are dynamic model of innovation at the meso level, institutional development trajectory of economic activity and the innovation chain of added value, together allowing to simulate "bunch type" of innovations diffusion process, results' and costs' parameters of innovation activities (added value and transaction costs). The model of innovative chains of added value within the framework of modern management concepts and accounting tools of synergetic theory allows more accurately (than at the enterprise level) allocate critical for sustainable innovative development of meso-systems trends, to identify priority "permitted states" (rules of innovative behavior) and generate a set of dynamic keys of management (bifurcation points). Program impact on management keys provides the required vector of innovative development of the system. The choice of strategy is the main mechanism of "bifurcation points" occurrence in which the split the trajectories of institutional transformation take place and strategic development prospects are predetermined.

Modeling of industrial chains of added values in the best degree enables visually to present the development options and threats' assessment to provide the continuity of meso-systems functioning, in case of the existing innovation models' improvement and their adaptation to the cyclical nature of the economy. Developing chains' simulation for the industry description (economic activity type), including clusters, let's take into account the so-called "bunch type"(a variation of the functioning script) of individual units (processing within the macro-technology) that contribute to the effectiveness of inter-industrial stepwise transition of the flow of added value along the macro-technological chain. Let's draw a diagram of view of supply chains with the presence of "bunch type" of individual units (figure 2). Specifics of cyclical (and its manifestation in the form of crisis) refer to a situation where fluctuations in industrial subsystems can lead 
to destruction of the existing institutional framework of industrial and cross-industrial interactions of market participants. Therefore, for the model of the innovation chain of added value it is necessary to explain the reasons and to allocate the institutional mechanisms to ensure the innovations' growing impulse, taking into account that a similar situation will arise throughout the chain of macro technology. The nodes of the circuit, in case of their alternativeness and belonging to different meso-systems (figure 3) mean the analogue of the bifurcation point, effecting a change (rise or fall) of the current production efficiency at the meso-, macro-, mega-levels of economic systems.

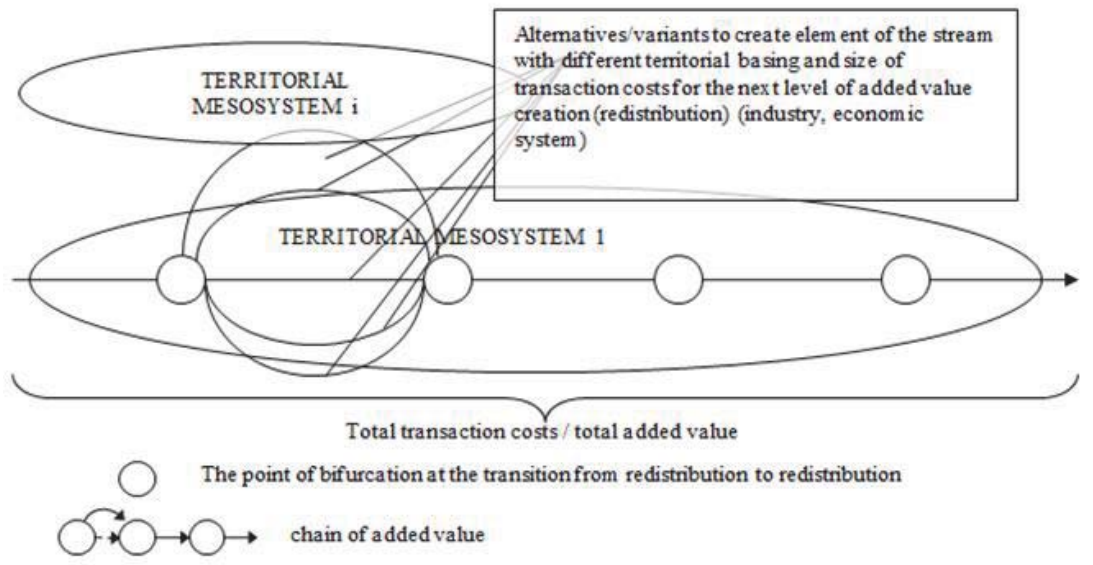

Figure 3. Bunch type model of the added value chain within the framework of macro-technology

The model is realistic and for industries with a high concentration of production, with the ability to extract the scale effect. The presence of bunch type at several stages of the supply chain determines the task of choosing the optimal path network model of added value creation, coupled with minimal losses (transaction costs) for the integral control of the object. Principal in this situation is the management of institutional trajectory because of its alternativeness: elements of innovation process, or if it moves to a new higher level of organization - the level of dissipative structures. For such a system to exist and develop, more energy (transaction costs) than for simpler structures is required. The entropy of the innovation system in this case can be estimated based on the magnitude of transaction costs, nonlinearly associated with the order of the innovation process, because only if there is optimal interval loss of added value, correlated with the costs of coordination, the entropy of the system will correspond to an economically efficient level.

Therefore, the basis of the institutionalization of innovative development must be the creation of incentives for innovations in the form of corresponding mutations of enterprises' routines; the development of mechanisms to improve the efficiency of transaction costs of an innovative nature in the form of compensation of a part of transaction costs in the functioning of supply chains; the internalization of positive externalities of innovation by the developers to mitigate the spill-over effect.

In its turn, solving the problems of sustainable stimulus to the generation of innovative changes is associated with the implementation of a compensation mechanism at the base level of the Institute of institutionalization - enterprise. It is important to be involved in this mechanism of its employees, positive externalities of which, on the one hand, is the increase the enterprise's efficiency, on the other hand - the assigned by the entrepreneur a part of accessions as a result of innovative activity of added value. In response to this or anticipating the externalities of innovation-active employees, the entrepreneur - the owner of the company - should allow them to internalizing externalities - i.e., to provide more income. In the case of an existing saving on wages in conditions of market failure discourage of innovative activity of enterprises occurs.

\subsection{The proposed approach to the effectiveness evaluating of the institutionalization of sustainable innovative development}

The need in new methodological solutions in the field of research on the effectiveness of sustainable economic development of innovative economic systems is reasoned by several circumstances: modern management models 
involve the simultaneous consideration within the model of innovative development of such dialectically interrelated factors such as innovation and competitiveness of the market, resulting to the emergence of the phenomenon of market's competitiveness reducing while the implementation by individual firms of innovative behavior because of the market power increase; the effectiveness of innovation activity for open and closed economic systems is varied (traditional values of efficiency indicators are often higher in the situation of barriers' presence to entry for competitors in meso system); the growth of traditional indicators of economic activity efficiency is observed in the situation of a number of market exchanges' reducing that eventually leads to the degradation of the innovation environment; in the study of innovation efficiency in accordance with the magnitude estimation of transaction costs as a methodological approach to the study of macro - and meso-economic systems, it is important to take into account the greater value of the specific transaction costs which are characteristic for acts of innovative exchange; for innovative activity a situation of positive externalities is natural, when the benefit from innovative developments not fully belongs to the developer, and therefore, at the micro level it requires additional costs to protect $R \& d$ results from the point of view of the market approach, an alternative one is a hand-out approach; the assessment of the sustainability of economic development, and, therefore, forecasting in the short term is problematic, because innovations mean the disruption of the balance.

The proposed methodology is based on an approach and a set of methodological decisions in the field of the effects' and costs' assessing of innovative economic systems' functioning. The approach is based on the identified parameters of the innovations' dynamic model and management institutional synergy model of sustainable innovative development involving positive externalities of innovations. In comparison with existing methodological approaches based on the use of economic system's profit as an indicator of the innovative project's effect, the proposed solutions are based on the accounting by the generated innovative system of added value (the share of innovative products in the revenue as derived indicator); in the diagnostic process of innovations' costly indicator it is proposed to allocate in the structure of enterprise expenditure on $\mathrm{R} \& \mathrm{~d}$ and operating costs of innovative projects the transaction costs (along with the transformation costs). Obtained values of the indicators require methodological correlation with the nature of industry innovation in the whole, which allows estimate the heterogeneity and the need of transaction costs (losses) and transaction costs of traditional and innovative activities. Table 1 shows two ways of the effectiveness' evaluation of sustainable institutional development of economic activities' types and their interpretation.

Table 1. Evaluation model of the sustainable innovative development effectiveness

\begin{tabular}{|c|c|c|c|}
\hline \multirow[b]{2}{*}{ Indicators } & Low-tech industry & The high-tech industry & Medium-tech industry \\
\hline & \multicolumn{3}{|c|}{$\begin{array}{c}\text { Industries are located in the direction of market power increasing and the market competitiveness } \\
\text { reducing }\end{array}$} \\
\hline$\overline{T A C / R}$ & \multicolumn{2}{|c|}{$51 \% \quad 47 \%$} & $36 \%$ \\
\hline AV/R & $27 \%$ & $53 \%$ & $37 \%$ \\
\hline IP/R & $5 \%$ & $10 \%$ & $8 \%$ \\
\hline \multicolumn{4}{|c|}{ The effectiveness of sustainable innovative development (Option 1) } \\
\hline IP/TAC & $10 \%$ & $21 \%$ & $22 \%$ \\
\hline \multicolumn{4}{|c|}{ The effectiveness of sustainable innovative development (Option 2) } \\
\hline AV/ TAC & $53 \%$ & $113 \%$ & \multirow{3}{*}{$\begin{array}{l}\quad 103 \% \\
\text { Medium - effective and low resistant } \\
\text { development } \\
\text { Negative transaction effect of innovation } \\
\text { development: partially mitigated by market } \\
\text { power }\end{array}$} \\
\hline $\begin{array}{l}\text { A comparison of the } \\
\text { sustainability of developmen }\end{array}$ & $\begin{array}{l}\text { The most inefficient } \\
\text { development }\end{array}$ & $\begin{array}{l}\text { The most effective } \\
\text { development }\end{array}$ & \\
\hline $\begin{array}{l}\text { Nature of transaction effect } \\
\text { of innovative development }\end{array}$ & $\begin{array}{l}\text { Negative transaction effect } \\
\text { of innovative development }\end{array}$ & $\begin{array}{l}\text { Positive transaction effect of } \\
\text { innovative development }\end{array}$ & \\
\hline
\end{tabular}

TAC - transaction costs, AV - added value, $R$ - revenue from sales of products, IP - revenues from sales of innovative products.

Interpretation of specific quantitative estimates of the sustainable innovative development's effectiveness is possible in the form of comparing of these indicators for groups of high, medium and low-tech sectors in the situation of the inverse U-shaped relationship's presence between the level of innovative activity and the type of market structure.

\section{Discussions}

To the study of innovative developments models of countries, regions and separate companies a significant number of fundamental and applied research papers are devoted (Leydesdorff, 2005; Lazonick, 2006; Mensch, 1985; Perez, 1985; 
Silverberg \& Verspagen, 1985; Krugman \& Venabies, 1995). Some of them are based on the provisions of neo institutional theory (Nelson \& Winter, 1982; Shinkevich, 2005; Williamson, 1985; Katkalo, 2003).

However, in spite of the presence of extensive methodological and theoretical data and practical solutions there hasn't been still developed a uniform methodology of the institutionalization of sustainable innovative development at the meso level, which would combine the latest achievements of modern management science and take into account the essential specifics, deformation and the imbalance of innovative processes in the Russian economic system.

\section{Conclusion}

The importance and relevance in stimulation of innovative development of meso-systems is not doubtful, and so it is more relevant in conditions of global crisis phenomena in the economy. However, ongoing governmental measures to increase the innovation activity of economic sectors are diverse and not always the most effective and modern, they do not account for institutional features of the functioning of the economy.

Therefore, in the framework of the studies the existing models of innovation development, management technologies, appropriate to different paradigms and levels of government were summarized and systematized. As a result an integral conclusion was made about the relevance to use in the process of modernization of the Russian economy of institutional approach aimed at the exerted added value's maximizing on the meso-level.

As a result of the implemented stages of the study the following consolidated results were obtained: the model of the innovative development for meso-level was proposed, a typology of institutions of innovative development was developed; the technology of institutionalization of sustainable innovative development was offered and the methodology for efficiency assessment of meso-systems' modernization for different levels of economic activities was developed.

Article materials - managerial and methodological solutions are of practical value for the following fields and sectors of innovation development: regulation and monitoring authorities of enterprises' innovation activities, bodies of regional innovation infrastructure and technology transfer for innovation-active enterprises in the field of refining manufacturing, etc.

\section{References}

Baumol, W. J. (1990). Entrepreneurship: Productive, Unproductive and Destructive. Journal of Political Economy. 98 (5), 893-921.

Katkalo, V. S. (2003). The original concept of strategic management and their modern evaluation. Russian management journal, 1, 7-30. Kleiner, G. B. (2006). New institutional Economics: towards a "supernew". Russian management journal, 4(1), 113-122.

Kleinknecht, A. I. (1987). Innovation patterns in crisis and prosperity: Schumpeter's long cycle reconsidered. Macmillan, London. Krugman, P. \& Venabies, A. (1995). Globalization and the inequality of nations. Quarterly Journal of Economics. 110 (4), 857-880. Lazonick, W. (2006). Theory of innovative enterprise. Economic Bulletin of the Rostov state University, 4 (3), 7-32.

Leydesdorff, L. (2005). The triple helix model and the study of knowledge-based innovation systems. International Journal of Contemporary Sociology, 42, 1-16.

Mensch, G. (1979). Stalemate in Technology: Innovations Overcome the Depression. Cambridge, Mass.: Ballinger Pub.

Nelson, R. \& Winter, S. (1982). An Evolutionary Theory of Economic Change. University of Illinois at Urbana-Champaign's Academy for Entrepreneurial Leadership Historical Research Reference in Entrepreneurship. Available at SSRN: http://ssrn.com/abstract= 1496211

Perez, C. (1985). Toward a Comprehensive Theory of Long Waves. Long Waves, Depression and Innovation: Implication for National and Regional Economic Policy. Laxenburg (Austria).

Schumpeter (1982). Theory of economic development. Translation from German. V. S. Avtonomov, M. S. Lubskoy, A. Y. Chepurenko. Moscow: Progress.

Shinkevich M. V. (2012). Effectiveness management of meso-systems development on the basis of the institutional approach. Management in Russia and abroad, 1, 38-44.

Shinkevich, A. I. (2005). Improvement of the institutional system of innovation development of the regional industrial complex (on the example of Republic of Tatarstan). Kazan: Publishing house of Kazanski. University.

Silverberg, G. \& Verspagen, B. (1995). Evolutionary Theorizing on Economic Growth. MERIIT. Maastricht, August.

Tatarkin, A. I. \& Romanova, O. A. (2008). Industrial policy: a theoretical framework, the regional experience of development and implementation. Industrial policy in the Russian Federation, 7. URL: http://www.prompolit-press.ru/0807.files/doc/3.doc

Williamson, O. (1985). The Economic Institutions of Capitalism. Free Press. 